This article is (c) Emerald Group Publishing and permission has been granted for this version to appear here (http://epress.lib.uts.edu.au/research/handle/10453/10498). Emerald does not grant permission for this article to be further copied/distributed or hosted elsewhere without the express permission from Emerald Group Publishing Limited.' 


\title{
Benefits of participating in accreditation surveying
}

\author{
1.Judith LANCASTER, BA LLB (Hons I), M.Bioeth, Grad.Cert. H.Ed., RN \\ 2.Jeffrey BRAITHWAITE, MIR (Hons I), MBA, PhD, FCHSE, FAIM \\ 3.David GREENFIELD, B. Sc., B.Soc. Wk., B.A., Grad. Cert. IT., PhD
}

\section{Autobiographical note}

Judith Lancaster is a PhD candidate in the Centre for Clinical Governance Research, University of New South Wales, Australia. She has cross-disciplinary qualifications in law and nursing. Her current research is an ethnographic study of the benefits associated with accreditation surveying. This work is a part of an Australian Research Council Linkage Project between the Centre and Industry Partners. Judith is also a part-time Senior Lecturer in the Faculty of Law, University of Technology, Sydney, Australia, where she has been awarded two Vice-Chancellor awards for teaching. Judith has served as a member of working parties set up by the Attorney General of NSW to make recommendations about various aspects of the legal profession.

Professor Jeffrey Braithwaite is Director, UNSW Institute of Health Innovation, Director, Centre for Clinical Governance Research, and Professor, School of Public Health and Community Medicine, University of New South Wales, Australia. His research inquires into the changing nature of health systems, particularly the structure and culture of organisations, attracting funding of more than \$17 million. He has published multiple times in the British Medical Journal, The Lancet, Social Science \& Medicine and many other prestigious journals. Jeffrey has received numerous national and international awards including a Vice-Chancellor's award for teaching from UNSW and his paper on organisational restructuring, published in Health Services Management Research, was one of the top fifty management articles in 2006.

Dr David Greenfield is a Research Fellow in the Centre for Clinical Governance Research, University of New South Wales, Australia. His research interests include community of practice, innovation and change in health services, organisational culture and climate, leadership, learning and knowledge management and health service accreditation. David is working on a major research study examining inter-professional learning and inter-professional practice. In addition, he supervises $\mathrm{PhD}$ students and is a reviewer for academic journals.

Data to date: at 29 August 2008

Words in body: 3,503

Words in abstract: 299

Tables: 5

Figures: 1

References: 27 


\begin{abstract}
Purpose - This paper explores how surveying benefits accreditation surveyors and the organisations in which they are regularly employed. The purpose is to examine from the perspective of senior executives who pursue this form of secondary professional activity, what they seek from being surveyors and what they believe they gain from the experience. This study is important because almost all accreditation programs world wide rely on external surveyors, and yet we know little about them.
\end{abstract}

Design/methodology/approach - The data were collected from recorded interviews with three senior area health executives who also serve as accreditation surveyors for the Australian Council on Healthcare Standards. The interviews comprised a series of open-ended, semi-structured questions. One hour was allocated for each interview. The questions were designed to explore why senior executive health professionals seek secondary professional activity as surveyors and their perceptions of the benefits they gain from surveying.

Findings - The benefits derived from surveying as a secondary professional activity fall into four categories. Firstly, it exposes the surveyor to new methods and innovations. Secondly, it provides a unique form of ongoing learning. Thirdly, it serves as a resource for acquiring expertise to enhance quality within the institutions in which the participants were regularly employed and finally, it provides opportunities to contribute to the process of quality improvement and enhance public health beyond the organisations in which the participants were regularly employed.

Practical implications - This research identifies a key aspect of the accreditation process that has not been the focus of previous research. It provides a reference point for understanding the value of surveying to the surveyor and to the institutions in which they are regularly employed.

Originality/Value - The paucity of existing literature on the role of the surveyor - both pre and post accreditation - makes this topic timely and significant. 
Keywords: Accreditation, Accreditation Surveyors, Influence, Quality Improvement

Paper type: Research paper

\section{Introduction}

It has long been accepted that accreditation surveyors bring a range of skills and experience to the accreditation process by virtue of their primary roles as health care professionals and in many cases managers within the health industry. The question of whether they derive benefits from their secondary professional activity as surveyors has not been previously examined. A preliminary premise of this research is that surveyors acquire from their active role in accreditation surveying a broad understanding of quality improvement issues and a degree of expertise at implementation of quality initiatives. They, therefore, take back to the organisations in which they are regularly employed evaluative expertise that can enhance the quality framework and processes which is of benefit both to those organisations and their own professional development.

Accreditation is an important process designed to contribute to quality improvement in health care facilities (Shaw, 2003). It has been central to the process of ongoing quality improvement ever since the process was first introduced in the United States following World War I (Roberts et al., 1987; O'Leary, 2000; Schyve, 2000). In Australia, accreditation is structured on a triangulated model involving internal evaluation and reporting, appraisal by a team of experienced external surveyors and final reporting by the appointed survey team (Braithwaite et al., 2006); (Braithwaite and Banks, 2008). The health care facilities in New South Wales, the state in which this study was undertaken, are administered by executive structures within geographically drawn zones known as area health services, which are similar to large NHS trusts with coverage of acute and community-based services. The senior executive members of each area health service are responsible for administering the strategic and operational functions under their control. Each area health service is accountable through its executive to both the Director-General and the Minister for Health for the delivery of satisfactory health care outcomes.

The participants in this research are employed by The Australian Council on Healthcare Standards (ACHS) and undertake surveying in conjunction with their usual professional roles in the area health service in which they are employed. ACHS is a private, non-profit provider of accreditation services to health facilities throughout Australia. Participants acquire from the survey process skills and 
expertise in quality improvement methods. Surveying, therefore, provides for learning that can translate into value for the primary workplace.

\section{The benefits of surveying}

Health professionals who take on surveying in conjunction with their continuing professional roles are well placed to derive the same benefits that a number of studies have shown to attach to servicelearning (Seifer, 1998; DiMauro, 2000; Witt and Heinrich, 2000; Forti and White, 2001; Canales and French, 2003; Baumberger-Henry et al., 2006; Brush et al., 2006; Reising et al., 2006; Lashley, 2007). Service-learning refers to placements in health facilities for the purpose of combining handson learning with community engagement while also providing necessary health care services to communities. It is a popular form of practical learning particularly in professional disciplines such as nursing and more recently in health administration programs (Sinay, 2000) The changing nature of health care services has prompted a move to embrace service-learning as an appropriate component of health administration education. Changes in the delivery of health services from hospital-based to community-based has generated demand for professionals to be familiar with local concerns. Similarly, resource constraints generate increasing demands for more comprehensive froms of accountability (Seifer, 1998; Forti and White, 2000).

Service-learning has a long track record of providing rich learning experiences from which flow considerable benefits to those involved (Dunn et al., 2000; Brush et al., 2006; Reising et al., 2006; Peabody et al., 2008). This includes benefits for the person serving in the placement, the individuals receiving the service and the broader community. The benefits include gaining insights into different approaches, building an appreciation of diversity and encouraging civic responsibility (Schyve, 1998; Brush et al., 2006; Baumberger et al., 2006). Other positive outcomes include "...involvement in efforts designed to change social systems and improve conditions that affect a nation as a whole..." (Canales and French, 2003, p.1232) and initiatives that have encouraged multi-disciplinary collaborations that provide services to areas of high priority community need (Peabody et al., 2008). There is thus, a strong possibility that the rich insights surveyors gain into quality improvement are a source of wisdom that can potentially benefit them and the institutions in which they are primarily employed. This area of accreditation surveying has not been examined.

Surveying is not an area that in the past has been considered or served as an educational opportunity for the health professionals who conduct the surveys. Similarly, external surveying is not usually undertaken as secondary employment for the purpose of satisfying professional development requirements. However, whether engagement in external facilities is for the purpose of practical learning or for reporting on a facility's performance for accreditation, there are opportunities for improved understanding and the facilitation of skill acquisition. The extent to which the participants in this research perceive surveying to be a source of these benefits is central to this study.

There is a plethora of research about the importance of accreditation (Bukonda et al., 2002; Pomey et al., 2004), identification of stakeholders (Taylor, 2001) and more recent papers arguing for the involvement of consumers in surveying (O’Connor et al., 2007). However, there is a distinct shortage of available work that documents either the role of surveyors, or their perceptions about the value of the experience gained from surveying within the professional environment in which they regularly work. The existing literature, much of which emanates from the United States of America, focuses on the performance of different organisations and their follow-up response. Generally it discusses the role of the accrediting bodies in the United States, in particular that of the Joint Commission. The Australian literature has also focused on institutional performance and responses along with the publication of accreditation guides and reports (ACHS, 2003). Although the process of addressing 
this particular aspect of accreditation is now under way (Greenfield et al., 2008) there is currently a paucity of available literature.

One study carried out in the Republic of South Africa prospectively measured the effects of an accreditation program on various indicators of hospital care (Salmon, et al, 2003). Although the information reported in this study contributes significantly to our understanding of an aspect of accreditation of which little was previously understood, the role of the surveyor was not examined. Another study canvassed surveyor's opinions of the problems and obstacles encountered in implementing quality management systems in Thailand, but not their opinions about surveying (Pongpitul, et al., 2006). A more recent study currently in progress in Australia seeks to identify how accreditation processes influence and reflect health care organisational quality by using a prospective, multi-method, multi-level, multi-disciplinary approach to assess the validity, impact and value of accreditation within the Australian health sector (Braithwaite, et al, 2006). Very little, therefore, is presently known about the extent to which surveyor training and active involvement in accrediting other facilities translates as a value-added resource for the surveyor in her or his usual professional role or for the facility in which a surveyor is regularly employed.

\section{Study Design}

Qualitative approaches are widely identified as an effective way to 'capture the meaning of everyday human activities' (Hammersley and Atkinson, 1989, p.2). They are credited with being able to provide researchers with an understanding of and control over situations with which they must deal (Glaser and Strauss 1967, 3). The study comprised in-depth interviews with three senior executives who undertake surveying as a secondary professional activity. Two of the participants were attached to large metropolitan area health services and one to a large regional service. Interviewing was selected for this research because of its capacity to locate the subtleties that shape perceptions the participants have about the value of surveying. This provides for the construction of an explanatory framework that aids understanding of what surveyors actually derive from their work as surveyors.

Data were collected by means of one hour audio-taped and documented interviews conducted by the principal author of this paper at the hospitals where each participant was regularly employed. Signed consent was obtained from each participant prior to the interview. The structure of the interviews comprised a mix of informal and structured, open-ended questions. Because surveyor influence may operate in any number of ways within the organisation and, for the surveyor it may operate at both implicit and explicit levels, the informal approach was favored for its capacity to draw more comprehensive responses and pick up subtle areas of surveyor perceptions which may not otherwise be achieved by the more structured or directive interviewing designs (Denzin and Lincoln, 2003, p.48; Fontana and Frey, 2003, pp. 64-70).

Participants were given an explanation of what each set of questions sought to address. They were encouraged to respond to specific questions in their own terms and, wherever necessary, to expand on their initial responses. This model is appropriate because the interviews sought to identify not only the less common practices but also to explore local issues in the context of a significant body of existing knowledge applicable to this study (Murphy and Dingwall, 2003).

Each interview commenced by asking participants to describe their perceptions about how quality is understood in the organisation and the extent to which they believe they influence the process. They were then asked to relate their thoughts about the value of the skills and experience gained from surveying. The aim was to encourage participants to consider the interface between the tasks associated with each role. Each interview proceeded with more specific questions designed to elicit 
participants' perceptions about what they sought from being external and the value of the knowledge and experience they gained from surveying and its utility to them in their professional roles (see Appendix, Figure A1).

\section{Participant selection}

Participants were selected from amongst surveyors who conduct surveys for ACHS on an occasional basis and in conjunction with employment as senior executives of area health services. All are employed in public area health services, two of which are in the Sydney metropolitan area and one in regional New South Wales. Each participant takes part in surveying under an agreement with the area heath services in which they are employed to release them from their professional executive roles for the periods when they are required to conduct an external survey as a member of a designated survey team.

Selection was designed to meet several requirements. Firstly, participants needed to be experienced in surveying procedures. This limited selection to those who had conducted a minimum of 10 surveys. This was important for establishing the perceptions formed from varied surveying experiences developed over a period of time. Secondly, the research focus was on surveyors whose regular professional occupation was as a senior executive in the area health. The reason for choosing this particular group was to focus on health professionals with a capacity to influence a broad range of service areas encompassing both management and clinical practice areas. Thirdly, logistic limitations required that the research be conducted within a 200 kilometer radius of the Sydney metropolitan area. Enrolled participants met these criteria. Two of the participants were interviewed at the area health executive units where they are located and the third participant was interviewed in the office of the principal author.

\section{Data analysis}

Each audio-taped interview was transcribed verbatim and coded by the principal author. The coding was carried out using a manual system of cataloging based on themes drawn from the literature on service-learning. Key statements about the value of the surveying process and what participants believed to be the benefits of their surveying activities to themselves and to the organisatisations in which they were regularly employed, were identified from participant responses. These statements were grouped under corresponding themes. The themes were then formulated into the the four categories of benefits listed below .

\section{Ethical dimensions of the study}

Following approval by the University of New South Wales Research Ethics Committee and the consent of each area chief executive, information documents were sent to each of the participants. These documents explained the purpose and intended use of the research and a full explanation of procedures to be followed to ensure privacy protection of the recorded data. Consent and consent revocation forms were included.

\section{Demographic features}

All three subject participants held senior executive positions within their area health service - two of the participants were attached to the medical executive and one to the general executive teams. The two medical executives had been employed in their roles for more than five years. The other participant had served as a member of the general executive group for eight years. All three subject participants had worked within the health industry for between thirty and thirty five years and they 
had been engaged as occasional surveyors for eight, nine and fifteen years respectively. Table I contains relevant demographic information.

Table I Experience of surveyors

\begin{tabular}{llll} 
Demographic & Participant $\mathbf{1}$ & Participant $\mathbf{2}$ & Participant $\mathbf{3}$ \\
\hline Time working in the health Industry & 30 years & 35 years & 35 years \\
\hline Time as a surveyor & 15 years & 8 years & 9 years \\
\hline Number of surveys undertaken & 30 & 15 & $20+$ \\
\hline
\end{tabular}

\section{Findings}

The analysed data revealed that the participants considered surveying to be an ideal way for them to achieve multiple aims. Each expressed a belief that exposure to different approaches to quality in different institutions provided unexpected benefits that were not a conscious part of their initial decision to become a surveyor. These benefits were found to fall into four categories identified from the data as corresponding with those associated with service-learning. These were: firstly, having exposure to new methods and innovations; secondly, engagement in a unique form of ongoing learning; thirdly, acquiring expertise to enhance quality within the institutions in which the participants were regularly employed and fourthly, translating surveying expertise into contributions to the process of quality improvement and enhancement of public health beyond the organisations in which the participants were regularly employed. Specific statements made by the participants about each of these benefits are set out in the tables numbered II to V below.

Table II Exposure to new methods and innovations

\begin{tabular}{|c|c|}
\hline Participant 1 & $\begin{array}{l}\text { "The experience I have gained from being a surveyor has been useful in my } \\
\text { everyday work in the organisation. I find I always bring some idea back or I learn } \\
\text { something. At one stage I became an expert in medical staff by-laws for small } \\
\text { private hospitals. I became an expert in medical appointments and credentialing for } \\
\text { small private hospitals. So when people say to me "you don't understand how the } \\
\text { private sector works”, I can give them a long talk about how I might actually have } \\
\text { some credentials in that area and probably know as much as they do." }\end{array}$ \\
\hline Participant 2 & $\begin{array}{l}\text { "Where being a surveyor is very helpful is where health care tourism comes into } \\
\text { play - being able to observe what happens in other organisations and developing a } \\
\text { better understanding of the whole business of quality improvement. I would say } \\
\text { absolutely that the experience gained from being a surveyor is directly useful } \\
\text { because it allows for one to develop a deep understanding of what is being done in } \\
\text { other organisations and to speak with authority about it. You learn as you do } \\
\text { surveys." }\end{array}$ \\
\hline Participant 3 & $\begin{array}{l}\text { "Even when you're talking to somebody about something you often don't even } \\
\text { realise that you bring up issues or you give them information because you might } \\
\text { have seen how others do it elsewhere, or because you know the requirement. Or it } \\
\text { might just be when I'm sitting here talking to one of my managers about something. } \\
\text { I think things come out all the time.” }\end{array}$ \\
\hline
\end{tabular}

Table III Surveying as a unique form of ongoing learning

Participant 1 "I see surveying as a way to get regular practice at thinking things through from a


systems point of view, keeping up to date with the standards and making quick assessments against those standards. It also tests my writing skills. The main reason I do surveying for ACHS really is for my own opportunities for learning.”

Participant 2 "I don't think there is anything intrinsic to being a surveyor. But once you have surveying experience it does help you with what you do everyday. I also think that having someone around who can help assess our compliance is very useful.”

Participant 3 "I suppose the main contribution surveying allows me to make, as well as knowing the standards, is knowing we meet them or at least how to get there. I've got the knowledge of what other institutions are doing to meet them as well.”

Table IV Translating surveyor expertise within the organisation

\begin{tabular}{ll}
\hline Participant 1 & $\begin{array}{l}\text { "Surveyors themselves, by their characteristics, are often sought out as mentors. I } \\
\text { think my colleagues believe the surveyors influence the process of accreditation } \\
\text { within the organisation. They often seek my advice about interpretation and things } \\
\text { like that." }\end{array}$ \\
\hline Participant 2 & $\begin{array}{l}\text { "When it comes to our own accreditation, I look at everything before it goes in. I } \\
\text { then go out and talk to staff about it and they also come to me." }\end{array}$ \\
\hline Participant 3 & $\begin{array}{l}\text { "When you've done a few surveys and been to a few training days with ACHS, you } \\
\text { pick up lots of information you can bring back and put into your organisation. Also, } \\
\text { when situations arise where colleagues express misguided beliefs that they do not } \\
\text { have to comply with certain procedures I can then say "I know you do have to } \\
\text { because I am a surveyor and I know what has to be complied with to get accredited. } \\
\text { You can also point them towards material that will assist their understanding and } \\
\text { you can provide them with some education along the way." }\end{array}$ \\
\end{tabular}

Table V Translating surveyor expertise beyond the organisation

\begin{tabular}{ll}
\hline Participant 1 & $\begin{array}{l}\text { "The main thing is that surveying is all part of that concept of service. If we're } \\
\text { part of the whole health system and our job is to try and make it better then one } \\
\text { of our jobs is to participate with helping other organisations with these } \\
\text { activities. It’s all part of service." }\end{array}$ \\
\hline Participant 2 & $\begin{array}{l}\text { "What influenced me to become a surveyor was my intense interest in quality } \\
\text { improvement and governance, not just at work but throughout the health } \\
\text { system. If you think about it, quality is getting the care right and getting the care } \\
\text { right is my obsession." }\end{array}$ \\
\hline "My ability to be able to contribute in the broad sense makes the exercise of \\
being a surveyor very worthwhile for me, for my institution and for the worthy \\
goal of improving public health,"
\end{tabular}




\section{Discussion}

The interview data showed that the four categories of benefits the participants associated with surveying correspond closely with the benefits attributed to service-learning. By becoming surveyors and availing themselves of the opportunity to observe new methods and innovations and examine how they have been applied to improve quality in different institutional settings, participants were able to develop their practical knowledge base and expand the reach of their professional skills in unique areas identified in the literature on service-learning (Schyve, 1998; Eyler and Giles, 1999; Sinay, 2000; Witt et al, 2000; Baumberger-Henry et al., 2006; Reising et al., 2006; Peabody et al., 2008).

The data also indicated that external surveying benefits the organisations in which the surveyors are regularly employed in a number of ways. Firstly, it serves as a mechanism for health professionals to keep up-to-date with changing standards and the ways they are implemented in other institutions. Secondly, it provides a practical way for health professionals to develop deeper levels of understanding about quality and its implementation. Thirdly, the knowledge acquired through surveying is subsequently passed on to colleagues by way of mentoring (participant 1), overseeing preparations for internal accreditation (participant 2) and instigating awareness of new standards and other information relevant to the enhancement of quality (participant 3).

A strong element of civic responsibility was expressed by the participants along with a belief that surveying provides an avenue for its exercise both within the institutions in which the surveyors worked and beyond. Within their own institutions they draw upon the skills and experience acquired from surveying to assist colleagues to understand issues pertaining to quality improvement and accreditation. They also play a leading role in steering the overall compliance process. Similarly, there was a strong element of accepting responsibility to contribute to the enhancement of quality across in a broader context across the entire health service.

The participants believed that they gained valuable insights into different approaches to quality improvement from surveying and considered it a useful way for them to satisfy personal aspirations to exercise civic responsibility in the same way described in the literature on service-learning (DiMauro, 2000; Sinay, 2000; Witt and Heinrich, 2000; Forti and White, 2001; Canales and French, 2003; Baumberger-Henry et al., 2006; Brush et al., 2006; Reising et al., 2006; Lashley, 2007). The ability to contribute service beyond that required by their regular employment facilitated a drive amongst the participants to provide meaning and service to others. This, in turn, generated feelings of fulfillment and personal satisfaction indicative of the high levels of personal satisfaction other studies have found to be experienced by individuals involved in service-learning (Forti and White, 2001; Baumberger-Henry et al, 2006; Peabody et al., 2008 ).

By undertaking a secondary professional activity like surveying participants could fulfil their altruistic aspirations by harnessing the experience gained from surveying for the benefit of colleagues and the wider community. In doing so, the participants in this study demonstrated a clear pattern of what has been called "working smart - turn[ing] traditional teaching and service activities into scholarly products.”(Witt et al, 2000, p.7).

\section{Conclusion}


The data produced by this study provide primary information about the benefits derived from surveying. In particular, these findings identify what the benefits are and how they provide a valuable resource.

The findings highlight the fact that accreditation surveying exposes professionals who undertake it as a secondary professional activity to a broad range of practical experiences and insights into the dayto-day operation of health care in different facilities. These experiences provide a rich source of benefits for surveyors and for the organisations in which they are regularly employed. The findings also suggest that this aspect of surveying is not well undestood thereby suggesting that the full range of associated benefits remain relatively untapped.

The results of this study provide a reference point for understanding the value of surveying. They also highlight the need for more research into this important aspect of healthcare accreditation. This can provide organisations with the means to better understand the nature of the specialized skills housed in the health care professionals they have on staff who are also external surveyors

The corresponding author can be contacted at z3042878@student.unsw.edu.au

\section{References}

ACHS (2003), The EQuIP Guide: A Framework to Improve Quality and Safety in Healthcare Australian Council on Healthcare Standards, Sydney.

Baumberger-Henry, M. L., Krouse, A., Borucki, L.C. (2006),” Giving and Receiving: A Case Study in Service Learning”, Nurse Educator, Vol. 31 No. 6, pp.249-52.

Braithwaite, J. and Banks M. (2008) What does accreditation of a health service mean for patient care? In: Australian Commission on Safety and Quality in Health Care, National report 2008, Sydney, ACSQHC, pp 73-82 [http://www.safetyandquality.org/].

Braithwaite, J., Westbrook, J., Pawsey, M., Greenfield, D., Naylor, J., Iedema, R., Runciman, B., Redman, S., Jorm, C., Robinson, M., Nathan, S. and Gibberd, R. (2006), “A Prospective, multimethod, multi-disciplinary, multi-level, collaborative, social-organisational design for researching health sector accreditation”, BMC Health Services Research, Vol. 6, pp.113-23.

Brush, D.R., Markert, R.J. and Lazarus, C.J. (2006), “The Relationship Between Service Learning and Medical Student Academic and Professional Outcomes”, Teaching and Learning in Medicine, Vol 18 No 1, pp. 9-13.

Bukonda, N., Tavrow, P., Abdallah, H., Hoffner, K., Tembo, J. ( 2002), "Implementing a national hospital accreditation program: the Zambian experience” International Journal for Quality in Health Care, Vol. 14, Supp.1, pp. 7-16

Canales, M. K., and French, H. (2003), "Experiential Learning as Service for Others", Association of Operating Room Nurses. AORN Journal, Vol. 77 No. 6, pp.1232-39.

Denzin, N.K., and Lincoln, Y.S. (2003), "Methods of Collecting and Analyzing Qualitative Materials” in Denzin, N.K., and Lincoln, Y.S., (Eds.), Collecting and interpreting qualitative materials, Sage Publications Thousand Oaks, London.

DiMauro, N. M. (2000), “Continuous Professional Development”, Journal of Continuing Education in Nursing, Vol. 31 No. 2, pp.59-62.

Dunn, S. V., Ehrich, L., Mylonas, A., Hansford, B.C. (2000), “PhD Students' Perceptions of Field Experience in Professional Development”, A Comparative Study, Journal of Nursing Education, Vol. 39 No. 9, pp. 393-400.

Eyler, J. and Giles, D. (1999) Where's the learning in service-learning? Jossey-Bass, San Francisco. 
Fontana, A., and Frey, J.H. (2003), (Eds) “The Interview: From Structured Questions to Negotiated Text”, in Denzin, N.K., and Lincoln, Y.S., eds. (2003), Collecting and interpreting qualitative materials, Sage Publications Thousand Oaks, London, pp.61-107.

Forti, E.M. and White, A.W. (2001), “A Rural Service-Learning Model for Health Administration Education”, Journal of Health Administration Education, Vol 19 No4, pp.403-15.

Glaser, B.G. and Strauss, A.L. (1967), The Discovery of Grounded Theory: Strategies for Qualitative Research, Aldine Publishing Co, New York.

Greenfield, D., Braithwaite, J., Pawsey, M. (2008) “A typology of health care accreditation surveyor

styles” International Journal for Health Care Quality Assurance, Vol. 21 No. 5, pp. 435-43

Hammersley, M., Atkinson, P. (1989), Ethnography : principles in practice, Routledge, London.

Lashley, M. (2007), "Nurses on a Mission: A Professional Service Learning Experience with the Inner-City Homeless”, Nursing Education Perspectives, Vol 28 No 1: 24-26.

Murphy, E. and Dingwall, R. (2003), Qualitative Methods and Health Policy Research Social Problems and Social Issues, Aldine de Gruyter, New York.

O’Connor, E., Fortune, T., Doran, J., Boland, R. (2007) “Involving consumers in accreditation: the Irish experience” International Journal for Quality in Health Care, Vol, 19 No 5, pp. 296-300.

O'Leary, D. S. (2000) “Accreditation's role in reducing medical errors”, Western Journal of Medicine, Vol. 172 Iss. 6, pp. 357-58.

Peabody, C., Block, A. and Jain S. (2008), "Multi-disciplinary service learning: a medico-legal collaboration", Medical Education, Vol. 42 No 5, pp.533-4.

Pomey, M.P., Contandriopoulos, A.P., Franc,ois, P., Bertrand, D. (2004), “Accreditation: a tool for organisational change in hospitals? International Journal of Health Care Quality Assurance Vol. 17 No. 3, pp. 113-24

Pongpitul, K., Sriratanaban, J., Asavaroengchai, S., Thammatach-Aree, J. and Loaitthi, P. (2006), "Comparison of health care professionals' and surveyors' opinions on problems and obstacles in implementing quality management system in Thailand: a national survey”, International Journal for Quality in Health Care, Vol. 18, Iss. 5, pp. 346-51.

Reising, D.L., Allen, P. and Hall, S.G. (2006), "Student and Community Outcomes in Service Learning: Part 1-Student Perceptions”, Journal of Nursing Education, Vol. 45 Iss. 12, pp.512-15.

Roberts, M.D., James, S., Jack, G., Coale, M.A., Robert, R. and Redman M.A. (1987), “A History of the Joint Commission on Accreditation of Hospitals", Journal of the American Medical Association, Vol. 258 No.7, pp.936-40.

Salmon, W.J., Heavens, J., Lombard, C., and Tavrow, P. (2003), “The Impact of Accreditation on the Quality of Hospital Care: KwaZulu-Natal Province, Republic of South Africa”, University Research Co., LLC.

Schyve, P.M., Editorial, “Accreditation and Globilization” (1998), International Journal for Quality in Health Care. Vol. 10, No.6, pp. 467-68.

Schyve, P.M. (2000), "The evolution of external quality evaluation: observations from the Joint Commission on Accreditation of Healthcare Organisations", International Journal for Quality in Health Care, Vol. 12 No.3, pp. 255-58.

Seifer, S. (1998), "Service-Learning: Community-Campus Partnerships for Health Professions Education” Academic Medicine, Vol 73 No 3, pp. 273-77.

Shaw, C.D. (2003), Editorial, “Evaluating Accreditation”, International Journal for Quality in Health Care, Vol. 15 No. 6, pp. 455-56.

Sinay, T. (2000), "Service Learninng In The Undergraduate Health Administration Curriculum:Theory and Practice, Journal of Health Administration Education, Vol 18 No 4, pp. 357-70.

Taylor, B. (2001), Editorial, “Winning Hearts and Minds”, International Journal for Quality in Health Care, Vol. 13, No.3, pp. 173-75. 
National Health Performance Committee (2004), National report on health sector performance indicators 2003, AIHW cat. no. HWI 78, Australian Institute of Health and Welfare,Canberra.

Weiss, R.S., Learning from strangers: the art and method of qualitative interview studies, New York: Maxwell Macmillan International, 1994.

Witt, B. S., Heinrich, K.T. (2000), "Working Smart: Turning Everyday Commitments Into Scholarly Outcomes” Journal of Continuing Education in Nursing, Vol. 31 No.2, pp.71-75.

Appendix - Sample Interview Questions

General inquiry about what influence means and how it operates in the organisation

The intention here is to ask general non-specific questions to elicit the surveyor's view about how influence operates in the organisation and how much influence he/ she has over quality issues:

- Please describe what this organisation is like to work in

- Do you think there ways to make things happen in regard to quality improvements? Please consider this at both the area and the individual hospital levels.

- If you identify a situation at either level that you believe should be addressed in a certain way how do you go about influencing the outcome?

General questions to identify what prompted the move to become a surveyor and her/his views about whether the skills and knowledge acquired from the surveying experience translate into a valuable additional resource in the hospital in which they work.

The intention here is ask interviewees general non-specific question to identify if the surveyor feels she/he gains awareness of 'value-added' aspects from the experience of being a surveyor

- What influenced you to become a surveyor?

- Do you believe you have any influence over preparations for accreditation? If so,

can you describe the ways in which you exercise that influence?

$>$ would you trace the source of the influence to your expertise gained from being a surveyor or does it arise from other circumstances e.g. senior position in the organisation, length of time engaged in particular area etc.?

- Are there informal channels through which you might have influence

- Is the experience you have gained from being a surveyor useful in your everyday work at this institution? Please describe the ways in which it has helped

- Do you think you are consciously or sub-consciously influencing or trying to influence quality in some way in your workplace?

General questions about whether there are institutional expectations that particular contributions should be made by the surveyor staff member to quality committees and preparation for accreditation in the organisation

The intention here is to ask the interviewee/s a general non-specific question to elicit staff awareness of expectations that surveyors should make particular contributions to quality committees and preparation for accreditation in the organisation 
- Do you think your colleagues in the executive and throughout the hospitals expect you to be an expert on the accreditation process and quality issues in general?

- Have you taken on any additional roles or duties in regard to quality improvement and/or preparation for accreditation since becoming a surveyor?

- Do you have a designated role concerning the provision of information about accreditation and/or quality issues generally?

- On a scale of 1-7 how would you rate the amount of influence you believe you have on quality issues and preparation for accreditation in the organisation.

The study forms part of the research program into accreditation led by investigators in the Centre for Clinical Governance Research at University of New South Wales, Sydney, Australia. For this research the Centre has industry partners the Australian Council on Healthcare Standards, Ramsay Health Care and various consumer groups.

\section{Funding}

This research was supported under the Australian Research Council's Linkage Projects funding scheme (project number LP0560737).

\section{Acknowledgements}

This research was supported under the Australian Research Council's Linkage funding scheme (project number LP0560737), along with support from industry partners the Australian Council on Healthcare Standards, and Ramsay Health Care Ltd; and the Australian Private Health Insurance Association. These funding bodies had no role in the study design; collection, analysis or interpretation of data; the writing of this manuscript; and the decision to submit the manuscript for publication. 
